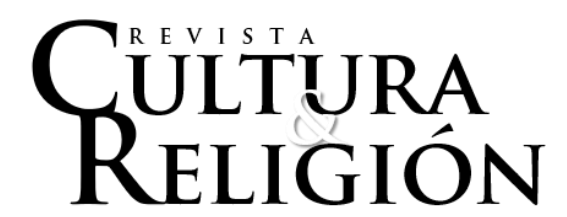

Vol. XIV, N 1 (2020) pp. 58-79

Recibido: 7 de agosto, 2019

Aceptado: 5 de enero, 2020

\title{
MUJERES Y LIDERAZGO EN LOS INICIOS DE LA IGLESIA ADVENTISTA DEL SÉPTIMO DÍA EN ARGENTINA Y SUDAMÉRICA (1894-1930)
}

\author{
Women and leadership during the initial appearance of the Seventh-Day \\ Adventist church in Argentina and South America (1894-1930)
}

\author{
Silvia Cristina Scholtus* \\ Universidad Adventista del Plata, Argentina \\ silviascholtus@gmail.com
}

\begin{abstract}
Resumen
Este artículo busca describir la participación de las mujeres que ayudaron a desarrollar y a consolidar la presencia de la Iglesia Adventista del Séptimo Día como una iglesia cristiana dentro del protestantismo, en Argentina, y por extensión en Sudamérica, a partir de las vinculaciones con las migraciones europeas del siglo XIX. Se toma como marco de referencia documentos de la propia iglesia y personales -que abarcan el período desde 1894 hasta 1930con el propósito de captar los matices de las experiencias de los sujetos para comprender sus perspectivas de interpretación de la realidad que buscaron plasmar. Entre los principales resultados surge el aspecto comunitario como una arista importante de transformación mediante el aporte de las mujeres, quienes llegan desde Europa y Estados Unidos para evangelizar. Si bien estas traen ideas progresistas, no logran deshacerse de conceptos ambivalentes de los roles de los sexos, los que influyeron en las primeras creyentes locales en tres dimensiones: la educación, la ética y la salud.
\end{abstract}

Palabras clave: Iglesia Adventista del Séptimo Día, mujer, liderazgo, Sudamérica, evangelización.

\footnotetext{
Abstract

This article describes the participation of women who helped establish and consolidate the presence of the Seventh-day Adventist Church as a Christian church within Protestantism. These events occurred in Argentina, and by extension in South America, given the links with 19th century European migrations. Documents from the church itself along with personal

* Doctora en Teología, Universidad Adventista del Plata. Docente de la Facultad de Teología de la Universidad Adventista del Plata (Entre Ríos, Argentina). Encargada de Centro Histórico Adventista, dependiente de la Universidad y de la Unión Argentina de los Adventistas del Séptimo Día.
} 
documents, and which cover the period from 1894 to 1930, are used as a reference framework in order to capture the nuances of the experiences of the subjects. The purpose of this is to understand their perspectives on the interpretation of the reality that they sought to capture. Among the main results, the community aspect emerges as an important feature of transformation through the contribution of women, who travelled to the country from Europe and the United States to evangelize. Although they brought with them progressive ideas, they did not manage to shake off ambivalent concepts regarding the roles of the sexes, which influenced the first local believers in three dimensions: education, ethics and health.

Keywords: Seventh-day Adventist Church, women, leadership, South America, evangelization.

\section{Introducción}

Estudiar la historia incluyendo la dimensión religiosa de sus participantes es una tarea importante para reconstruir los ideales de vida que guiaron a los individuos que formaron e influyeron en diferentes comunidades. En este artículo interesa particularmente estudiar la influencia de una entidad eclesiástica, como la Iglesia Adventista del Séptimo Día, en la vida, la voz y la acción de algunas de sus mujeres que colaboraron en la expansión de estas creencias cristianas en Argentina y Sudamérica entre 1894 y 1930. Sin la intrepidez y la dedicación misionera de estas mujeres, la realidad y la extensión e influencia de esta iglesia en la comunidad sudamericana actual sería muy diferente.

Para buscar estas historias de mujeres, se ha recurrido a bibliografía primaria de los relatos que aparecen en los registros de la propia Iglesia Adventista. Al hacer esta revisión, se ha percibido que el registro de los actores no ha sido completo, debido a que no se consideró su labor en el mismo nivel de importancia que el de los actores varones, particularmente en lo que concierne a la labor de las mujeres como evangelistas, docentes, promotoras de la salud y más. Desconocer su legado, proyectó un futuro con carencias que derivaron en interpretaciones teológicas y prácticas eclesiásticas que relegaron la labor de la mujer como inferior a la del hombre.

\section{Estado de la cuestión}

Como bien lo indica Seiguer (2010a), existe una historia que es necesaria reconstruir, debido al interés único de las colectividades de inmigrantes para valorar la situación del campo religioso en las décadas finales del siglo XIX y primeras del XX. Mayormente por su impacto en la historia posterior de Argentina.

De allí que han surgido aportes, más de un siglo después y desde diferentes perspectivas, para reconstruir esta historia. En los primeros años del siglo XXI aparecen estudios como el de Bianchi (2004), que hace una síntesis del panorama religioso no católico y el desarrollo de las religiones minoritarias en Argentina.

Los inicios de estas colectividades de inmigrantes que mantuvieron los valores religiosos y culturales de sus lugares de origen eran registrados por ellos mismos en literatura significativa. Esta literatura iba dirigida a un público muy reducido para obtener apoyo y fondos para el desarrollo de las misiones de otras comunidades protestantes asentadas mayormente en Estados Unidos y Europa. Otras publicaciones tenían el propósito de difundir sus creencias. Esta situación representó un intercambio ideológico "peligroso". En el período que compete al presente artículo, 1894 a 1930, la asociación liberalismo-protestantismo, 
afirma Seiguer (2010a), se presentaba como denuncia por parte de las publicaciones católicas. La Iglesia católica se sentía amenazada por el liberalismo religioso europeo; incluso en Argentina surgían tensiones porque quienes dirigían el Estado miraban con simpatía a las grandes potencias industriales de la época que eran protestantes. De allí el interés por promover un intercambio religioso y fomentar la inmigración.

En general, esta instigación de parte del catolicismo contra los conceptos religiosos de otros grupos étnicos generó una asociación de nacionalidad-religión, como bien lo detectó Seiguer (2010a). Se puede observar este fenómeno en diferentes lugares de Sudamérica donde existen colectividades de inmigrantes que promueven firmemente la cultura, el idioma y los conceptos heredados de sus lugares de origen. En algunos existen ocasiones festivas para promover el intercambio cultural y social.

Seiguer (2010a) analiza en detalle este aspecto que llevó a la ecuación argentino = católico, protestante $=$ extranjero, en diferentes ponencias (Seiguer, 2007, 2010a). No obstante, se han revisado las interpretaciones elaboradas en relación con el protestantismo histórico. Esto se debe a que la noción de trasplante de inmigrantes generó situaciones de adaptación a las circunstancias locales que ha producido recreaciones novedosas. Para Seiguer (2010a), esto impone desnaturalizar la identidad protestante de estos grupos y plantearse preguntas respecto a los roles que cumplieron estas iglesias, los valores que tuvieron y cómo se integraron a los individuos de la sociedad que los recibió.

Ante el duro proceso de adaptación de las colectividades de confesiones religiosas no-católicas, el Estado argentino promovió la creación de un registro civil para poder dar identidad diferenciada de la Iglesia católica. No fue hasta 1885, bajo la presidencia de Julio A. Roca, que el gobierno argentino creó el Registro Civil. Con anterioridad, todo el registro de datos de las personas recaía sobre la Iglesia católica, que en sus "libros parroquiales" llevaban las anotaciones de nacimientos, bautismos, matrimonios y defunciones (Pirota et al., 1991). Los inmigrantes que habían arribado al territorio argentino durante las décadas anteriores a esas fechas habían tenido serias dificultades para ser registrados, debido a que muchos de ellos no profesaban la religión católica. Incluso esto impedía que pudieran acceder a una educación formal, que generalmente estaba también en manos de la Iglesia católica, que no admitía a quienes no eran sus feligreses. Sin embargo, se percibe que el Estado argentino en su estado formativo buscó apoyar a las escuelas confesionales protestantes y católicas. Por otra parte, Seiguer (2010a), destaca el rol importante del protestantismo en propiciar la separación entre Iglesia y Estado, del libre ejercicio de cultos y propiciar la lectura de la Biblia en el ámbito educativo.

La ausencia de trabajos académicos que tengan en cuenta discursos diferentes a los generados por las propias élites dentro del interior de las iglesias hace necesaria la investigación del tema. También el análisis de la forma en que los individuos se insertaban en el rol asumido dentro de la comunidad, a pesar del intento por unificar un discurso y posicionarse como institución eclesiástica frente a las presiones culturales dentro del contexto argentino.

Algunas de estas presiones dentro de lo social y cultural en Argentina tuvieron que ver, según lo indican González-Bernaldo e Hilaire-Pérez (2015), con un proceso de circulación transnacional de conocimientos que involucraron etapas formativas de disciplinas diversas, y específicamente en el campo jurídico, fomentadas por iniciativas reformistas en la sociedad argentina. Estos tendían a configurar el papel del Estado y a desplazar principios del constitucionalismo liberal clásico.

Estos elementos provocaron un cultivo interesante de un entramado social y cultural 
propio en Argentina. Este entramado social y cultural también incluyó e influyó en los distintos grupos que sostenían creencias diferentes, producto de migraciones que fueron poblando Argentina desde sus inicios. Según indica Bastián (2006), es importante notar que fue recién a partir del siglo XIX y el comienzo de las independencias en Latinoamérica que empezó a dibujarse la posibilidad de otorgar una tolerancia religiosa para los extranjeros que migraban a esta región.

En las últimas décadas aparecieron varios estudios tendientes a estudiar los fenómenos del surgimiento e inserción de varias denominaciones protestantes y evangélicas. Por ejemplo, el caso de los evangélicos (Bastián, 2006; Ceriani Cernadas y Lavazza, 2017), los metodistas que buscaron una identidad nacional autónoma y antagónica al modelo propuesto por el catolicismo (Alba, 2007; Amestoy, 2007; Viano, 2011), los Hermanos Libres (Roldán, 2007), la Iglesia anglicana (Seiguer, 2009; 2010b; 2018), las misiones menonitas (Altmann, 2018), los Adventistas del Séptimo Día (Flores, 2018), entre otros. Estos estudios están inspirados en el deseo de describir la estrecha relación entre el protestantismo y el liberalismo económico, la flexibilidad de ajuste de estos movimientos con el clima intelectual que desafiaba a nuevos cambios, el optimismo y la confianza que dominaron estos siglos.

Dentro de estos estudios se ha visto el interés por revisar el rol de las mujeres en los grupos religiosos y su contribución a la sociedad en el marco de conceptos religiosos diferentes. Entre ellos están los trabajos de Amestoy (2012) en relación con los fundamentos y el espacio que los protestantes concedieron a las mujeres en el proyecto misionero que tenían; los registros de Scholtus (2013) sobre el trabajo de mujeres misioneras adventistas; el estudio de De la Fuente Stranger (2014) con respecto a las mujeres anglicanas; la investigación de Griffin (2014) sobre el espacio de las mujeres entre los pentecostales en Gauleguaychú, Entre Ríos; y también los escritos de Agundez Márquez (2018) y Mazariegos Herrera (2018), quienes relatan las vivencias personales de mujeres que desde sus conceptos religiosos influyeron en sus comunidades.

En este artículo se describe la forma en que las ideologías religiosas y sociales del período en estudio influyeron en la inserción de la mujer adventista dentro del ámbito eclesiástico y social en Argentina y Sudamérica.

\section{Ideologías religiosas y sociales de la época}

Ser la esposa de un misionero en las décadas en estudio era un rol codiciado, de allí que casarse con un hombre misionero fue, para muchas mujeres, vivir la aventura misionera. Una situación que no se da tanto en la actualidad, porque esto restringe a la mujer moderna en el desarrollo de su profesión y en lo social, pues las misioneras difícilmente podrían ejercer su profesión por estar subordinadas al rol de auxiliar de sus esposos pastores, a excepción de que la actividad misionera sea ejercida desde otras profesiones (por ejemplo, en áreas ligadas a la salud, la educación y otras).

El rol de las mujeres en la misión se requería en algunos lugares donde solo estas podían tener un trato directo con otras mujeres y con las familias. Esto propició la capacitación de las mujeres en diferentes áreas (salud, educación y otras) y brindó a las mujeres protestantes una oportunidad de la que ya gozaban las monjas católicas: poder ir a nuevos lugares para colaborar en la evangelización y la educación de la población (Amestoy, 2012).

Estas diferentes sociedades donde ingresaron las misioneras no estaban 
acostumbradas a ver a las mujeres en roles protagónicos y, mucho menos, con poder de decisión. No obstante, en general, la literatura de inicios del siglo XX destacaba los roles de la mujer como madre y compañera de su esposo. Lo que importaba era cuidar su rol materno. Así lo afirmaban las enseñanzas del catolicismo. Ella era madre y reproductora. A esto se sumaban los énfasis científicos en sus abordajes, que asignaban importancia a la mujer como madre y cuidadora de los hijos. Desde lo político, se relevaba el rol de la mujer en la formación de los ciudadanos varones futuros. Los grupos progresistas hablaban de la mujer como esposa y compañera que cuidaba del hogar y del descanso del varón. Estos conceptos también se encuentran presentes en la literatura evangélica (Griffin, 2014).

En este trasfondo también existían voces que pregonaban utopías anarquistas, que junto con el curanderismo criollo y el espiritismo de inmigrantes dieron voz y liderazgo a algunas mujeres, aunque se dificulta entender si proponían otra identidad para la mujer.

En todo este conjunto de voces fue imponiéndose y aceptándose los modelos de padre proveedor y madre ama de casa, que fueron propagados por el catolicismo conservador, el liberalismo político del Estado, el cientificismo de la medicina moderna (Griffin, 2014), el asentamiento de conceptos evolucionistas, el materialismo socialista, entre otros.

Para 1916, el reconocimiento a la labor femenina dentro del ámbito protestante llegó como consecuencia de los frutos de sus esfuerzos. Las mujeres misioneras extranjeras habían llegado a tener una presencia marcada en América Latina, al igual que el de las misioneras locales. También la cantidad de proyectos alcanzados por sus esfuerzos, se sumaban al poder económico que tenían las Juntas Misioneras creadas por mujeres (Amestoy, 2012). La primera junta misionera en la Iglesia adventista que enviaba publicaciones a otros países y que empezó a reunir fondos para el envío de misioneros al extranjero, surgió en Estados Unidos como un proyecto patrocinado por mujeres en 1868. El éxito del emprendimiento hizo que, para 1871, la Asociación General de los adventistas considerara importante este emprendimiento, nombrando a hombres encargados de promocionarlo, y dejando a las mujeres a cargo de los emprendimientos de los grupos locales. Se puede notar que se desplazó a las mujeres como encargadas principales de impulsar este proyecto.

No obstante, en 1913, la Iglesia adventista reconoció el rol de las mujeres en este emprendimiento misionero, el cual se fortaleció para enviar a muchos misioneros alrededor del mundo, y nombró a Edith Graham como secretaria del departamento misionero, el que se transformó en una oficina departamental en 1918 (Strayer, 2002). Es evidente que esta iniciativa contó con un apoyo económico no despreciable, muy similar a emprendimientos de otras juntas misioneras lideradas por mujeres en grupos de otras denominaciones (Amestoy, 2012).

Estos emprendimientos de las mujeres para la misión se percibieron como un aporte importante para la pronta difusión del evangelio cristiano en otros lugares. Amestoy (2012) señala que las misioneras asumieron la iniciativa de la tarea educativa de la mujer, en pos de que estas pudieran desarrollarse intelectualmente, accediendo a estudios secundarios y superiores. Con esto se buscaba demostrar que las mujeres no perdían dignidad o hacían peligrar sus hogares por dedicar tiempo a su desarrollo intelectual, en contraposición al pensamiento imperante en la sociedad patriarcal de esos años que consideraba que la mujer solo debía prepararse para el matrimonio, la familia y la vida social. Ese tipo de educación se brindaba en colegios católicos, situación que deja entrever que, aunque hubiera intenciones de superación de la mujer y de mayor participación social, todavía no se había logrado la pluralidad de participación. Los roles diferentes que debían ocupar hombres y mujeres seguían estando presentes y marcados por ideologías religiosas y sociales. 
Por un lado, las mujeres protestantes se disponían a no quedarse encerradas en las paredes de su iglesia o en instituciones educativas. Participarían en nuevas organizaciones sociales para crecer en cuestiones políticas, culturales y sociales (Amestoy, 2012). Particularmente, la Iglesia adventista siempre manifestó interés por participar en movimientos o ligas de templanza que incluían conceptos de salud y reformas en la vestimenta, y todo tipo de voluntariado para niños, ancianos y en instituciones de salud (Stacey, 2004; Gencer, 2010; James y Hamilton, 2011).

Por otra parte, el impulso que generaron las misioneras al insertarse en el contexto latinoamericano permitió mayores espacios de participación de la mujer en la sociedad, y con su evangelización produjeron también cambios sociales en pro de la modernización y el progreso de las mujeres. En el ámbito de lo eclesiástico, los espacios generados por las sociedades de mujeres favorecieron su capacitación. Lamentablemente, estos espacios propiciados por las misioneras extranjeras fueron desapareciendo con el liderazgo de las mujeres locales para las décadas posteriores a 1920. Pasaron de buscar influir en la sociedad a solo restringir su influencia en el ámbito eclesiástico. Fue difícil desarraigar de la mentalidad latinoamericana los conceptos tradicionales que se apegaban a circunscribir el influjo de la mujer solo al hogar. Volvieron así a un discurso conservador y dejaron de tener un rol protagónico en la sociedad por varias décadas.

Los espacios que supieron ocupar las misioneras extranjeras fueron dejados en manos de hombres que seguían imponiendo una mentalidad patriarcal, recluyendo a la mujer a los espacios del hogar y, en la Iglesia, solo a ocupar algunas actividades de beneficencia e instrucción religiosa de los niños. Es decir que, como también lo dedujo De la Fuente Stranger (2014), a pesar de las nuevas ideas de las misioneras extranjeras, estas también se quedaron en un modelo que se fundaba en la ideología de esferas separadas, que asignaba roles primordiales a hombres, el de proveedores, y a las mujeres, los de reproductoras y cuidadoras. Esta separación de roles influyó negativamente en algunos grupos étnicos, desmereciendo el empuje de las mujeres en algunas sociedades con su rol de proveedoras y se sacrificó la pluralidad en el acceso a la vida de la comunidad y de la política. Y, por eso, el evangelismo fracasó en algunas comunidades étnicas en las que los roles de los sexos no estaban fijados y en los que existía el pluralismo.

Según lo expresado, las construcciones ideológicas son un instrumento teórico que influye en la praxis cuando nace de una interpretación particular de textos bíblicos. La escasa participación a la que accedían las mujeres en los estudios teológicos dificultaba aún más la revisión de esas hermenéuticas que no hacían justicia a lo expresado completamente en el texto bíblico.

\section{Surgimiento de la Iglesia Adventista del Séptimo Día y su llegada a Sudamérica}

Los pioneros adventistas en Sudamérica no dejaron claramente plasmada la contribución de las mujeres a la vida eclesiástica y su plena participación, como lo muestra el registro histórico de esta denominación, al no incluir más relatos sobre las actividades de las mujeres. Es evidente que, en la mente de los primeros creyentes, todavía eran fuertes las influencias culturales y religiosas que los rodeaban.

En 1890, la Iglesia adventista hacía apenas dos décadas que había comenzado su expansión fuera de los Estados Unidos. Contaba con una membrecía mundial de 29.711 creyentes (Brauer, 2003). Los misioneros y las misioneras eran escasos. Apenas unos pocos creyentes pudieron venir al continente sudamericano. No obstante ser pocos, sus proyectos 
eran arrojados. Para comienzos del nuevo siglo ya habían organizado varias iglesias, congregaciones e instituciones de educación, salud y publicaciones. Esto se debió a que tanto los hombres como las mujeres colaboraron intensamente en la misión. Las mujeres que llegaron como misioneras solteras o casadas propiciaron tal visión de dedicación, esfuerzo y entrega, desarrollando sus habilidades y sus dones, que inspiraron a las nuevas generaciones de conversos.

Este fervor se asentaba en las mismas raíces de la Iglesia Adventista del Séptimo Día, cuyo origen se remonta a un movimiento enraizado en los grandes despertares religiosos de principios del siglo XIX que se dieron en varios contextos estadounidenses y europeos. Se puede afirmar que los primeros adventistas eran protestantes que compartieron ideas que estaban presentes en la sociedad de ese entonces y las revisaron bíblicamente para formar una iglesia que los congregara, proceso que duró dos décadas aproximadamente (Spalding, 1961).

Estos movimientos de reavivamientos propiciaron la predicación del laicado, lo que permitió el acceso de la mujer al púlpito, que había sido un terreno vedado anteriormente. No obstante, la situación predominante fue que la mujer siempre fue un auxiliar del hombre. Un rol de subordinación que, desde lo religioso, llevó al reclamo social en favor de los derechos de la mujer. Estos se basaban en los derechos naturales y la estructura se asentaba en la convicción religiosa de que Dios había creado por igual a los dos primeros adanes, varón y mujer, con la posibilidad de desarrollo pleno de todas sus facultades. El término hebreo adam -que significa "hecho de la tierra"- designaba su origen y destino, determinando su clasificación entre las especies creadas. Posteriormente, el segundo adam mujer recibió un nombre, Eva, que indicaba su rol importante de futura dadora de vida del nuevo adam, que revertiría las consecuencias ocasionadas por "la caída" del ser humano, según la promesa bíblica registrada en el libro del Génesis (3:15-20).

En general, en Europa se vivían tiempos de crisis económicas debido a las guerras. De allí que muchos buscaban migrar a nuevos lugares, mayormente ubicados en América. En esos tiempos turbulentos también se dejaba sentir la influencia de diferentes ideas liberales y descristianizadoras (Auger, 1986; Carballo, 2017; Escobar, 2017). Ya en 1878, en el marco de un espíritu democrático que se estaba extendiendo en la sociedad norteamericana y siguiendo varias ideas reformistas relacionadas con la emancipación femenina, con prácticas igualitarias producto de la renovación traída por los reavivamientos religiosos de los años 1830 a 1840, la escritora estadounidense y cofundadora de la Iglesia Adventista del Séptimo Día, Ellen Harmon White, describió la necesidad del trabajo de las mujeres en la misión de la Iglesia Adventista de la siguiente manera:

Women of firm principle and decided character are needed [...] They should feel that they are engaged in an important work in spreading the rays of light which Heaven has shed upon them. Nothing will deter this class from their duty. Nothing will discourage them in the work. They have faith to work [...] Sisters, God calls you to work in the harvest field and help gather in the sheaves. (White, 1978, p. 1)

También dijo el 26 de julio de 1910, en una de sus cartas publicadas posteriormente en uno de sus libros (White, 1978), que la tarea de difundir el evangelio era para todos los creyentes y que no era exclusiva de algún grupo genérico en particular: "Intelligent women, if truly converted, can act a part in this work of holding Bible classes. There is a wide field of service for women as well as for men" (White, 1910, parr. 4, White para A. G. Daniells, 
24 de julio de 1910). Esta autora, clave en la historia de la Iglesia adventista, favoreció que la mujer no estuviera solo en su rol en el hogar. Las siguientes son algunas de sus declaraciones:

God has blessed woman with talents to be used to His glory in bringing many sons and
daughters to God; but many who might be efficient laborers are kept at home to care for
their little ones. (White, 1885, p. 753).

Seventh-day Adventists are not in any way to belittle woman's work. If a woman puts her housework in the hands of a faithful, prudent helper, and leaves her children in good care, while she engages in the work, the conference should have wisdom to understand the justice of her receiving wages. (White, 1898, parr. 4)

The way is open for consecrated women. But the enemy would be pleased to have the women whom God could use to help hundreds binding up their time and strength on one helpless little mortal that requires constant care and attention. (White, 1898, parr. 9)

Esta era también una tendencia social de igualación que se extendía hacia el área educativa y de acceso al conocimiento. En general, los protestantes favorecieron el igualitarismo en lo social mediante el abolicionismo y los nuevos roles femeninos (Amestoy, 2012). Dentro de este marco, fue que se favoreció el sacerdocio universal de los creyentes, que incluía a las mujeres. Esta fue una creencia importante para la misión dentro de la Iglesia adventista (Andrews, 1884; Office of Archives, Statistical and Research [ASRT], 2016).

Dentro de este marco los adventistas surgieron en Argentina diseminados en diferentes grupos de inmigrantes protestantes que manifestaron interés por conocer las creencias adventistas. Fueron épocas que se distinguieron por continuar implementando las leyes de inmigración (Fernández, 2017), basadas en el objetivo de atraer ideas progresistas, aunque los inmigrantes europeos trajeron también consigo ideas socialistas, anarquistas y sindicalistas; vale decir, que los adventistas no surgieron en Argentina por un trasplante de inmigrantes que tenían estas creencias. Se produjo por un trasplante de misión para fortalecer y expandir el interés encontrado en Argentina, para así establecerse como grupo con identidad propia dentro del sector de Sudamérica. Estos conceptos de "trasplantes" corresponden a la propuesta de Villalpando (1970), que buscó diferenciar los tipos sociológicos de iglesias de origen inmigratorio de las de origen de misión.

En 1890 llegaron a Argentina los primeros misioneros de trasplante. Eran cuatro familias que conocieron las creencias adventistas en Estados Unidos y decidieron compartirlas con amigos y conocidos que habían migrado a Argentina. En 1891 arribaron otros tres misioneros que se dedicaron a difundir literatura adventista. Dos años más tarde llegó una pareja de misioneros, Richard Craig y su esposa, quienes se establecieron en Buenos Aires. Durante su permanencia, abrieron una pequeña escuela para la enseñanza elemental a los hijos de misioneros de habla inglesa.

En 1894 arribaron Mary Thurston de Westphal y su esposo Frank Westphal. Este fue el primer misionero con credencial que le permitía organizar y bautizar en nombre de la Iglesia adventista en Sudamérica. La pareja asumió la tarea de la familia Craig, que regresó a Estados Unidos. Se establecieron en una zona poblada mayormente por gente de habla inglesa, que incluía a comunidades de origen británico (irlandeses, escoceses y galeses) en Estación Solá, cerca de los ferrocarriles Roca. Allí había varios inmigrantes británicos que se encargaban de trabajar para establecer y extender las vías férreas en Argentina, impulsadas por los gobiernos de corte progresista y liberal. Estos inmigrantes alentaron la revolución 
agraria y la revolución industrial. Para la década de 1890, la Argentina ya contaba con más de 16.000 km de vías (Gobierno de la Ciudad Autónoma de Buenos Aires, 2010).

Por lo tanto, los misioneros adventistas se insertaron dentro de una comunidad que los acogió por hablar una lengua similar y tener una mentalidad de progreso y desarrollo intelectual. Era una época en que los adventistas sentían el fervor por difundir sus creencias más allá de Estados Unidos. Al igual que otras denominaciones cristianas de ese entonces, los motivaba el deseo de difundir el evangelio "hasta lo último de la tierra" (Greenleaf, 2011). Por eso llevaban registros de las misiones "extranjeras", como se denominaba a las misiones fuera de Estados Unidos (Historical Sketches of the Foreing Missions of the Seventh-day Adventists, 1886).

Los misioneros adventistas que llegaban a un país mayoritariamente católico debían definir nuevas estrategias para el entorno en el que se encontraban, junto con aprender un nuevo idioma y una nueva cultura. Mientras lo hacían, se acercaron a comunidades más afines con lo que pensaban, es decir, a grupos que hablaban su idioma y que provenían de culturas protestantes. Al ser iniciadores de un nuevo lugar de la misión adventista, tenían que acomodar sus prácticas y elegir a sus líderes locales. Eso habilitó a que las mujeres asumieran un rol preponderante en las primeras décadas, debido a que todavía no había líderes locales formados. Las mujeres vieron la posibilidad de contribuir en distintas áreas. El concepto que traían de misión era universal, no estaba restringido a un grupo étnico específico. Esto se observa en el hecho de que los adventistas llegaron a entender que su misión debía trascender las fronteras de su propio país para extenderse al mundo, llevando consigo un mensaje que consideraban único. En su autobiografía, una escritora adventista, Otilia Peverini de Ampuero, describió el trabajo de varias misioneras en Sudamérica:

Admiro a Florencia [Nightingale], Teresa de Calcuta, y otras muchas que con denuedo lucharon en favor del doliente, a pesar del entorno desalentador en que actuaron; pero me entusiasma y llena de gratitud a Dios la obra integral que desarrollaron mujeres como Ana Stahl, Guillermina Kalbermatter, Jessie Haliwell, Iris de Dalinger y otras que actuaron en Sudamérica. Inspiran sus vidas abnegadas y plenas de amor hacia el doliente. (Peverini de Ampuero, s.f, p. 80)

El esfuerzo por difundir las creencias cristianas adventistas no fue tarea fácil. Sus conceptos abiertos, progresistas y modernos respecto del rol de la mujer estaban en oposición a las ideas que dominaban los pastores y líderes de la región. Esa fue la razón por la que permanecieron relegadas en sus funciones administrativas y eclesiásticas. No obstante, a diferencia de otros grupos protestantes (Amestoy, 2012), se notó, en la búsqueda realizada, que las mujeres tuvieron voz y voto en asambleas oficiales y fueron elegidas representantes de su zona eclesiástica, aunque en Sudamérica se les restringió todavía el ministerio pastoral. Eso quiere decir que no se distanciaron completamente de conceptos tradicionales y patriarcales imperantes en cuanto a las funciones del hombre y la mujer.

Con el transcurso del tiempo, se levantó una barrera contra la inclusión de las mujeres en distintos cargos, lo que les permitíó acceder al voto y participar de las decisiones importantes respecto a la marcha de la misión eclesiástica. Eso se hace evidente actualmente, en la Iglesia Adventista, en la escasa representatividad que la mujer tiene, no solo en puestos administrativos, sino también en la representación en congresos y sesiones, donde se realizan tomas de decisiones. Esta representatividad surge de porcentajes establecidos en diferentes regiones eclesiásticas para los candidatos que tienen voz y voto, y que son mayormente 
hombres porque ocupan cargos en puestos pastorales y como ancianos en las iglesias distritales. Esta representatividad no es acorde con la membrecía que, en un porcentaje mayoritario, corresponde a mujeres. Por ejemplo, en Sudamérica, este porcentaje es del $56,5 \%$, con diferencias entre países que superan este número (Iglesia Adventista del Séptimo Día, 2017).

En las décadas en estudio, una de las dificultades que formaron parte del entorno desalentador que enfrentaron las misioneras adventistas fue que, la sociedad argentina en general, consideraba que la mujer no debía desarrollarse intelectualmente ni manejarse fuera de su hogar. Aunque trajeron las posturas "ambivalentes" marcadas por los reavivamientos religiosos que favorecieron la participación y el reconocimiento de la mujer, en Argentina este protestantismo sostuvo conceptos tradicionales que favorecían los roles femeninos de corte patriarcal (Amestoy, 2012). Aunque en sus inicios las creencias adventistas impulsaron los conceptos bíblicos que describían una antropología que consideraba el cuerpo humano como entidad completa e indivisible en el desarrollo de todas sus facultades (sociales, físicas, intelectuales y espirituales, fueran hombres o mujeres y también al sacerdocio universal de los creyentes), en la práctica y a su llegada a la zona rioplatense no destacaron este concepto (Andrews, 1884; ASRT, 2016).

Esto representó todo un desafío. Ya en 1881, la Iglesia adventista resolvió a nivel mundial que las mujeres podían ser ordenadas al ministerio por el éxito que estaban teniendo como evangelistas:

Resolved, That females possessing the necessary qualifications to fill that position, may, with perfect propriety, be set apart by ordination to the work of the Christian ministry. This was discussed by J. O. Corliss, A. C. Bourdeau, E. R. Jones, D. H. Lamson, W. H. Littlejohn, A. S. Hutchins, D. M. Canright, and J. N. Loughborough, and referred to the General Conference Committee. (Smith, 1881, p. 392)

Esto trajo aparejados ideas y prácticas divergentes. Había quienes apoyaban esta iniciativa y quienes mantenían los conceptos culturales de denominaciones anteriores, ya que los iniciadores de la Iglesia Adventista del Séptimo Día en Estados Unidos pertenecieron a distintos grupos religiosos de la época (Vance, 1999; Bull y Lockhart, 2007; Timm, 2012, 2014). Muchos de ellos provenían de grupos religiosos que propiciaron el movimiento restauracionista, que pretendió restaurar las doctrinas originales bíblicas en diferentes grupos del protestantismo.

Estos conceptos conformaron el marco para el cambio cultural que promovieron los creyentes adventistas en las áreas de educación, salud y ética en los orígenes del adventismo del séptimo día en Sudamérica, pues, como dijera Amestoy, "impulsaron un modelo de mujer que buscaba flexibilizar la idea patriarcal y favorecieron la modernización de la sociedad" (2012, p. 51) mediante la fundación de instituciones educativas, de salud y otras en las que las mujeres podían hacer sus aportes a la sociedad civil.

En relación con lo anteriormente descrito, las misioneras adventistas no dejaron de compartir el concepto de responsabilidades propias del sexo, según el pensamiento extendido en la época, y abordaron la "cuestión de la mujer" centrándose en las nociones de dedicación a lo doméstico y la maternidad. Esto aumentó su carga, al reformular e incorporar las nociones de otras responsabilidades frente a los procesos de modernización y luchas que se generaban por cambios para disminuir la violencia hacia su sexo y las posibilidades de acceder a desarrollarse en lo intelectual, como lo proponían los conceptos bíblicos. Cabe 
recordar que una de las fundadoras del adventismo del séptimo día a nivel mundial fue una mujer, Ellen $\mathrm{H}$. White, a quien se la reconoce por sus amplios escritos que propician y enfatizan los aportes que la mujer puede hacer en el ámbito eclesiástico y social. Sus textos son fuente de muchas reformas en el ámbito de la alimentación, la salud, la educación y las prácticas eclesiásticas que caracterizan a los adventistas.

Aunque estos cambios en las responsabilidades de la mujer no tuvieron en sí mismos la intención de subvertir las relaciones de género, avalaron ciertas mutaciones de signo moderno en la condición femenina, entre ellas, las que implicaban una inserción pública a través de la beneficencia e incluso impulsaron los aportes de las mujeres en la misión. No todos los consejos dejados por esta mujer fueron puestos completamente en práctica. De hecho, ella abogó por la ordenación de mujeres al ministerio (Fortin, 2013) e incluso favoreció que recibieran pago por su trabajo de los diezmos, algo que estaba destinado exclusivamente al rol pastoral masculino: "The tithe should go to those who labor in word and doctrine, be they men or women" (White, 1899, p. 3). ${ }^{1}$

En resumen, las primeras misioneras adventistas que se registran en el continente sudamericano tuvieron una influencia creciente que mostró un modelo de mujer que dinamizaba y cooperaba de diferentes formas en la difusión del evangelio debido a la falta de recursos humanos. Se presentan seguidamente lo que se ha podido reconstruir revisando registros de algunas de estas mujeres.

\section{Mujeres, misioneras y líderes en los comienzos de la Iglesia Adventista del Séptimo Día en Sudamérica}

Uno de los emprendimientos de los primeros misioneros y misioneras adventistas que llegaron a Sudamérica fue obrar diligentemente para proveer una educación que capacitara por igual a ambos sexos y los preparara en la difusión de sus creencias cristianas. Sobre todo, porque para un adventista era vital saber leer para acercarse al texto bíblico y tener una comprensión personal.

No obstante, la educación ofrecida mostraba los sesgos de influencia del concepto de roles de hombres y mujeres, y seguía su curso en los estilos patriarcales que marcaban la cultura. Los cursos ministeriales eran para los varones. Aunque el resto de los cursos prácticos y teóricos que dictaban eran para ambos géneros (Brown, 1953; La voz del Colegio, 1926).

Entre estos cursos prácticos para ambos géneros estaba la actividad denominada "colportaje", que refería a la venta de libros religiosos (Biblias, revistas adventistas, libros y panfletos) como forma de difundir las creencias adventistas. Durante esas ventas, los colportores podían observar las dificultades en la educación de la población argentina al igual que el grado de analfabetismo que, en algunas provincias, llegaba a ser de más del $70 \%$ (Consejo Nacional de Educación, 1946).

Otro aspecto a considerar fue el hecho de que ellos vendían literatura en los idiomas inglés, francés y alemán, lo que hizo que buscaran los sectores de la población argentina donde se hablaran esos idiomas. Este factor propició que los primeros misioneros se ubicaran en zonas cercanas a poblaciones de habla inglesa. Este fue el caso de Buenos Aires, donde surgió la primera escuela adventista en el hogar de Richard Craig. La tarea de la enseñanza

\footnotetext{
${ }^{1}$ Ver además, Rodríguez (2010).
} 
recayó inicialmente en mujeres. Primero fue la esposa de Craig y posteriormente otras misioneras. Entre ellas, Mary Thurston de Westphal y E. Threadgold. Estas misioneras estaban resueltas a continuar la educación de sus hijos. Este aspecto no es menor, pues fue gracias a estos emprendimientos que las mujeres difundían las creencias adventistas (Brown, 1953; Peverini, 1988).

Después de transcurrida la primera década de la llegada de los primeros misioneros, a raíz del rápido crecimiento de la feligresía en Sudamérica, la Asociación General de la Iglesia Adventista del Séptimo Día, con su sede en Estados Unidos, organizó, en abril de 1901, a la feligresía del continente sudamericano en una región geográfica denominada la Unión Misión Sudamericana, actualmente la División Sudamericana. Esta abarcó tres misiones: la Misión de Brasil, la Misión Argentina (conformada por Argentina, Paraguay y Uruguay) y la Misión Chilena (conformada por Chile, Perú, Bolivia y Ecuador). Es interesante leer los registros históricos de este "continente olvidado", como lo llamó Frank Westphal (1927), quien relató en su libro que no solo los hombres fueron partícipes de la aventura de difundir el evangelio en Sudamérica, sino también las mujeres. Westphal denominó "continente olvidado" a Sudamérica, porque en su época todo lo que se escuchaba sobre el progreso del adventismo tenía relación con Europa, África, Australia y Asia (Spalding, 1947, 1961).

Aunque las mujeres jugaron un papel muy importante en el desarrollo de la Iglesia Adventista del Séptimo Día, lamentablemente los registros históricos disponibles en esta iglesia se quedaron cortos o no registran la realidad por completo. Son escasos o breves los relatos que cuentan del esfuerzo de las mujeres en esa época. Esto es un indicador de que la influencia de las ideas sociales y políticas de aquel tiempo se dejaron sentir, en alguna medida, en la naciente iglesia en Sudamérica. Hubo mujeres solteras que abrieron nuevos lugares de asentamientos adventistas mediante su evangelismo. Muy poco se comenta del esfuerzo de aquellas pioneras que acompañaron a sus esposos a diferentes territorios de Sudamérica que eran desconocidos, y donde les tocó educar, criar y hasta perder a sus hijos. Y mientras lo hacían, muchas veces solas durante largos meses por causa del trabajo de sus cónyuges, con su entrega apoyaron y fortalecieron el cometido de difundir las creencias adventistas. Ellas fueron una influencia fuerte en los nuevos grupos de creyentes locales, bajo su liderazgo inspiraron y llevaron adelante nuevos emprendimientos, y suplieron las necesidades en aumento de una iglesia en crecimiento. No obstante, generalmente, aparecen ocultas tras la figura de sus esposos. Muy pocos de ellos registraron el esfuerzo de sus propias cónyuges. Las mujeres parecen no haber sido consideradas en muchos relatos históricos denominacionales. Escasos han sido los intentos por rescatar esta parte de la historia, sin la cual esta queda incompleta o mutilada. Hanna Norheim dijo que "cuando las mujeres como grupo son pasadas por alto, son también descalificadas y se crea la idea de que no han tenido una influencia significativa en la iglesia cristiana" (Norheim, 2009, p. 17).

El presente artículo solo hace un recorrido general para señalar que existe una tarea por hacer: recuperar la historia. Las mujeres que aceptaron las creencias de la Iglesia adventista en los primeros años en este continente, sin importar su formación educativa, participaron activamente en la misión. Por ejemplo, varias salieron a trabajar distribuyendo el periódico La Verdad Presente y Señales de los tiempos. En el primer periódico se hacía un pedido a que las mujeres se involucraran en el trabajo de evangelismo mediante la distribución de literatura adventistas (La Revista Adventista, 1906a, 1906b; Fulton, 1908). Según los informes de las juntas de las diferentes regiones de las misiones, se otorgaron "licencias misioneras" a aquellas mujeres que dedicaban su tiempo completo a difundir el 
evangelio en diferentes territorios de los países de Sudamérica.

Los informes provenientes de Argentina (Mangold, 1907; Brouchy y Brouchy, 1915) y de Chile relataron cómo las mujeres colaboraron con la distribución de literatura (Steele, 1906; Thomann, 1907). Estos informes mencionados contienen relatos personales, no obstante, un recorrido por los primeros años, 1901 a 1910, da cuenta de los informes de las ventas del colportaje, en los que figuran nombres de mujeres que hacían de esta tarea un trabajo exitoso. En Chile, por ejemplo, se destacó la obra de Olga Thomann de Fernández (Westphal, 1908). Aunque algunas de ellas no se trasladaban grandes distancias para hacer este trabajo, sin embargo, aprovechaban para hacer suscripciones a las revistas adventistas dentro de su localidad. El éxito de esta tarea en varios lugares llevó a que se escribieran varios pedidos en La Revista Adventista para solicitar que más mujeres adventistas se involucraran en sus localidades o vecindarios. Por ejemplo, aparecen comentarios sobre el trabajo de Elvira de Foley en la ciudad de La Plata, Buenos Aires, y de una joven de apellido Brown en Rosario, Santa Fe (La Revista Adventista, 1916). Varias fueron colportoras de éxito en Argentina, Uruguay y Paraguay. Estas mujeres decididas obtuvieron, mediante la labor del colportaje, sus propios medios de subsistencia e incluso se pagaron sus estudios terciarios, mientras evangelizaban.

Otra destacada contribución del liderazgo femenino en la historia de la Iglesia adventista tuvo que ver con el apoyo económico. Las mujeres no solo fueron colportoras evangelistas, sino que contribuyeron con sus donaciones para suplir las diversas necesidades económicas propias del crecimiento institucional de esta iglesia. Por ejemplo, la compra de de equipamiento para la imprenta adventista de Chile, que había sufrido daños por un incendio (Westphal, 1906).

La obra de sostener el crecimiento interno de la iglesia demandó e involucró el esfuerzo de las mujeres, tal como en la actualidad. Esta tarea incluía el trabajo con los niños, los jóvenes y los adultos en las reuniones de culto que hacían los sábados y que denominaban "escuelas sabáticas". Algunas mujeres oficiaron de directoras locales en las iglesias de esta actividad educativa, y otras fueron las primeras encargadas de los departamentos que empezaban a formarse en diferentes áreas de las misiones, asociaciones y uniones de la Iglesia adventista en Sudamérica.

En forma similar a lo que acontecía a nivel de la Asociación General de la Iglesia adventista en Estados Unidos, la tarea de administrar distintos departamentos de las uniones y asociaciones o misiones estuvo a cargo de hombres y mujeres. Existen varios registros que muestran que las mujeres colaboraron encargándose especialmente de dirigir los departamentos de Escuela Sabática, Actividad Misionera Local, el Departamento de Jóvenes, Sociedad de Jóvenes y Tesorería. Por ejemplo, en Chile, en el Departamento de Escuelas Sabáticas y Obra Misionera Local, María Thurston de Westphal, y en el Departamento de Sociedad de los Jóvenes, Catalina Block (Westphal, 1915; Thomann, 1915, 1916). Con posterioridad, fue nombrada Calista N. de Emmenegger como secretaria de las escuelas sabáticas y de la obra juvenil (Berchín, 1918). Más ejemplos se encuentran en Brasil, cuando la Conferencia de Santa Catarina y Paraná eligió a María de Ehlers como secretaria y tesorera de esa asociación (Spies, 1908).

Para tener una idea sobre el alcance de este tipo de liderazgo administrativo, se registra a continuación un resumen de los primeros años, que abarcan aproximadamente desde 1894 hasta la década de 1930.

En 1894, la primera pareja de misioneros fue enviada a la denominada Unión Misión Sudamericana. Mary T. de Westphal se encargó desde los inicios de la administración de este 
nuevo campo eclesiástico de la Iglesia adventista en diferentes aspectos, debido a la falta de recursos humanos. En los siguientes años fueron llegando más mujeres que también se dedicaron a diferentes labores de liderazgo y evangelización. A medida que transcurrió la primera década se fue avanzando en cuestiones de organización del territorio.

En 1906, lo que se llamaba Unión Misión Sudamericana se organizó como Unión Asociación y también se abrió el primer departamento de la Iglesia adventista en Sudamérica, el de educación, que estuvo ese año a cargo de Arturo Fulton. Al año siguiente se nombró a Ottena de Fulton como encargada de un nuevo departamento, el de Escuela Sabática, para el campo que abarcaba Argentina, Paraguay y Uruguay; y a María Thurston de Westphal para Chile, Bolivia, Perú y Ecuador. Ottena de Fulton fue nombrada la primera encargada del Departamento de Escuela Sabática al momento de la sesión bienal de la Unión Sudamericana, realizada en marzo de 1908 (Town, 1908a).

Cuando Luisa Post de Everist fue elegida encargada de ese departamento para la Unión y para la Asociación Argentina en 1910, encontró que existían 25 escuelas sabáticas en la Unión. El Departamento de Escuela Sabática estuvo a cargo de mujeres hasta 1919 en la Unión Sudamericana, y en las diferentes divisiones regionales que abarcaba esa Unión hasta cerca de 1930. Por ejemplo, se pueden agregar los nombres de Lydia Greene de Oppegard para la Unión Austral; María Thurston de Westphal, Sadie Graham de Town, Ottena de Fulton, Luisa P. de Everist, señora Haak, María de Casebeer, Clara de Baer, Maude de Perry, Teresa Krieghoff, señora Wilcox, señora Ernenputsch y Christina T. de Meier para la región Central de la Asociación Rioplatense hasta el año 1931. En Chile, a María de Westphal le siguieron Calista N. de Emmenegger, Gertrudis de Davis y Catalina de Hancock hasta el año 1926. En Uruguay, el Departamento de Escuela Sabática estuvo primero a cargo de Ottena de Fulton y luego le siguieron: Clara M. de Maas, Maude de Perry, Carlotta Hugo, Lydia Greene de Oppegard, Hilda O. de Koch, hasta el año 1920. En Paraguay comenzó Ottena de Fulton y le siguieron: Cecilia Deggeller de Kalbermatter; María de Ernst y Lydia G. de Oppegard, también hasta el año 1920. En Buenos Aires, el Departamento se inicia en 1921 y estuvo a cargo de Clara H. de Baer, y luego la señora Hancock hasta 1929 (Brown, 1953).

En noviembre de 1913 se votó organizar el Departamento de Obra Misionera Local, que comenzó a funcionar en 1914. Se nombró a Luisa Post de Everist como encargada, además de tener ya a su cargo el Departamento de Escuela Sabática desde 1910. La Asociación de Chile nombró a María Thurston de Westphal para ocupar ese puesto. Como se puede observar, el liderazgo para el crecimiento de la iglesia también fue llevado a cabo por mujeres en diferentes responsabilidades a medida que la misión de la iglesia lo requería.

Otra actividad que las mujeres emprendieron con dedicación se concentró en el área de la salud. Algunas trabajaron como enfermeras y aprovecharon, desde su trabajo, las oportunidades que les surgían para compartir lo que dice la Biblia sobre este aspecto. Por ejemplo, se relata el caso de la señorita Praun, en Progreso, Santa Fe (Town, 1908b), y de varias enfermeras graduadas que respondían al pedido de ayuda de la Conferencia Unión Sudamericana para difundir las creencias de la Iglesia adventista en las ciudades populosas del Río de la Plata. Las primeras enfermeras llegaron de otros países, como Estados Unidos y México (La Revista Adventista, 1909). Entre ellas se cuentan Adela Allen, esposa de Roberto Habenicht, y Ana, la esposa de Fernando Stahl. También Margarita Klatt trabajó como enfermera en el sur de la provincia de Buenos Aires, y cuando no atendía a enfermos, colportaba (La Revista Adventista, 1915). En Corrientes, Argentina, Adela de Brouchy trabajaba a la par de su esposo en la atención de enfermos (Brouchy y Brouchy, 1915). 
La tarea de evangelización realizada por las mujeres en el área del colportaje, la salud y la administración de la iglesia no quedó solo allí. La Iglesia adventista necesitaba de quienes pudieran escribir artículos y noticias para las revistas de difusión general. Desde los mismos comienzos de las revistas La Verdad Presente y El Faro hubo varias mujeres que contribuyeron redactando o traduciendo artículos para los diferentes periódicos. Algunas de ellas llegaron a ser jefas de redacción de la casa publicadora, como Lydia Greene de Oppegard, quien se encargó de La Verdad Presente y El Faro durante los años 1903, 1904, 1906, 1907; y de La Revista Adventista y Salud y Vida, desde 1910 hasta 1916 (Fulton, 1907; Oppegard y Oppegard, 1908; La Revista Adventista, 1910; Brown, 1953).

Y qué decir de la enseñanza. Qué sería actualmente de la Iglesia adventista sin la dedicada y empeñosa labor de cientos de maestras, directoras de escuela primaria, maestras de costura, de arte culinario, de música; preceptoras en los internados de colegios e instructoras bíblicas. Entre los primeros alumnos del primer colegio superior de Sudamérica figura una mujer, Emma Köhli, que trabajaba como maestra entre los primeros adventistas. Se mencionan como preceptoras a Margarita Ernst, la señora Lude, Luisa Hugo, Ida de Gil, y otras (John, 1911). La escuela primaria de Florida, Buenos Aires, Argentina, se inició en 1913 con tres alumnos. La inauguración de la escuela se realizó el 15 de marzo de 1916, y la señora Kirstein fue nombrada maestra y directora (Scholtus, 2013). A lo largo de los años y del crecimiento de la misión, se mencionan varias mujeres que fueron instructoras bíblicas. Algunas fueron contratadas específicamente para esa tarea, como Carlota Hugo en Uruguay, quien fue instructora bíblica (Westphal, 1916). Otras ayudaban a sus esposos en su tarea pastoral, y parte de su colaboración incluía dar estudios bíblicos. Por ejemplo, Adela de Brouchy (Brouchy, 1916).

En 1915, se registró que en los países de Perú, Bolivia y Ecuador había varias mujeres dedicadas al crecimiento de la misión adventista y la difusión del evangelio. Algunas trabajaban a la par de sus esposos y otras como empleadas solteras. Por ejemplo, en Ecuador estaban las esposas de los pastores Knight y Osborne. En el Perú, Cecilia de Kalbermatten, la esposa de Benjamín Rojas, la esposa de Stauffer y la señorita Carner. En la Misión del Lago Titicaca, Bolivia, Ana de Stahl, la señora Pohle, Margarita Ernst de Schulz, y la señorita Wightman (Maxwell, 1915).

\section{A modo de conclusión}

Como ya se vio, las mujeres realizaron labores de evangelistas, atendieron las necesidades internas de la iglesia preparando materiales y recursos humanos, y participaron en emprendimientos de educación y salud.

Actualmente, sigue siendo un desafío importante para la Iglesia adventista integrar en su relato histórico a las mujeres. Existen emprendimientos recientes que buscan lograr esto, pero son escasos (Scholtus, 2013; Plenc, Scholtus, Di Dionisio y Becerra, 2012).

El legado que dejaron estas mujeres quedó oculto, cuando no olvidado, aunque los frutos de sus esfuerzos perduran en el tiempo y se evidencia en el fuerte desarrollo administrativo, de instituciones educativas y de salud que caracterizan a la Iglesia adventista en el continente sudamericano. Actualmente, esta iglesia cuenta con una membresía de aproximadamente dos millones de miembros, unas 10.600 iglesias, 936 instituciones educativas, 15 campus universitarios, 19 hospitales y clínicas, emisoras radiales y casas publicadoras.

Algunas de las primeras misioneras pudieron ejercer su liderazgo empoderadas por 
sus esposos y otros líderes de la iglesia. No obstante, se percibe que algunas de ellas sufrieron falta de apoyo a medida que la Iglesia adventista crecía en este continente. Es probable que la influencia de aspectos culturales y/o religiosos del entorno fuera paulatinamente restringiendo las posibilidades y la influencia de las mujeres dentro de la comunidad adventista. Esto se percibe en la historia de Luisa Post de Everist (Scholtus, 2013).

Actualmente, la Iglesia adventista pasa por un período de discusión acerca de la intervención plena de la mujer dentro de su ámbito eclesiástico en Sudamérica. Se restringe su participación a algunos roles, no así en otras regiones geográficas de esta iglesia a nivel mundial (por ejemplo, Estados Unidos, Europa, Asia). Estas diferencias con otras regiones han provocado discusiones acaloradas dentro del propio entorno eclesiástico que aún hoy siguen vigentes. Particularmente, la aceptación del rol de la mujer como pastora, y otros reconocimientos de los aportes que pueden esperarse y que realizan las mujeres en diferentes áreas dentro del ámbito eclesiástico-administrativo. Y aunque no se tiene registro de que este tipo de reconocimiento lo recibieran las primeras misioneras que llegaron al continente sudamericano, su empuje da evidencias de que este reconocimiento estaba vigente en los lugares de donde provenían, es decir, Estados Unidos.

Hoy en Sudamérica, la mujer sigue haciendo aportes en las dimensiones de ética, educación y salud. Pero aún está ausente, pese a ser mayoría genérica dentro de la iglesia, en el ámbito administrativo donde puede tener voz y voto. Esto estaría desmereciendo el legado pionero de mujeres que marcaron con integridad y empuje la contribución que estas pueden hacer dentro de la comunidad eclesiástica y fuera de ella en la época presente, cuando las condiciones sociales de la mujer han mejorado en diferentes países sudamericanos.

En el área teológica, en la Iglesia adventista en Argentina y Sudamérica, recién en el año 2014, se extendió el título de nivel de posgrado doctoral a una mujer (Prensa UAP, 2014). Posteriormente, le siguieron dos más. No obstante esto, la dificultad por acceder a estos ámbitos hace que las que obtienen un título de grado en Teología, busquen títulos de posgrado en otras especialidades (educación, administración). Aunque, aun así, no se observa un panorama claro y a corto plazo de integración de la mujer en la toma de decisiones en las áreas administrativas importantes fuera del ámbito de las iglesias.

Lo mismo ocurre con las escasas mujeres que se atreven a incursionar en el área teológica para hacer aportes. Recién en 2017, un grupo de mujeres tituladas de teología propusieron un encuentro para quienes tenían intereses comunes en el área de Argentina y Sudamérica (Prensa UAP, 2017). En 2019 se realizó un segundo encuentro.

Empero la falta de pluralismo y de las restricciones a sus posibilidades de hacer contribuciones más amplias en esta denominación, es notorio el interés de las mujeres por el trabajo como misioneras locales y en el extranjero, aun sin por ello ser reconocidas.

\section{Referencias bibliográficas}

Agundez Márquez, M. A. (2018). Religiosidad gris en la vida cotidiana de una soltera evangélica: el caso de Solag. El Protestantismo: perspectivas antropológicas. 5(7), 38-69.

Alba, M. A. (2007). Difusión del Protestantismo en la ciudad de Buenos Aires (1870-1910). El caso Metodista. Teología y Cultura. [En línea]. Recuperado de: http://www.teologos.com.ar/historia.htm

Altmann, A. (2018). Echar raíces: el impacto del "giro antropológico" de las misiones 
menonitas en el caso argentino (1940-1960). Nuevo Mundo Mundos Nuevos. [En línea]. [Consultado el 10 de diciembre de 2018]. Recuperado de: http://journals.openedition.org/nuevomundo/74262 DOI: https://doi.org/10.4000/nuevomundo.74262

Amestoy, N. R. (2007). Los orígenes del metodismo en el Río de la Plata: las sociedades metodistas en el marco del liberalismo (1857-1901). Teología y Cultura. [En línea]. Recuperado de: http://www.teologos.com.ar/historia.htm

Amestoy, N. R. (2012). Las mujeres en el protestantismo rioplatense 1870-1930. Franciscanum, $\operatorname{LIV}(157), 51-81$.

Andrews, J. N. (1884). Seventh-day Adventists. The Present Truth, 1(1), 1. [Consultado el 10 de enero de 2020]. Recuperado de: http://documents.adventistarchives.org/Periodicals/PT/PT18840501-V01-01.pdf

Auger, I. (1986). Estados Unidos: "La nación conforme a Dios". Nueva Sociedad, (82), marzo-abril, 150-156. Recuperado de: https://nuso.org/media/articles/downloads/1381_1.pdf

Bastián, J. P. (2006). De los protestantismos históricos a los pentecostalismos latinoamericanos. Análisis de la mutación religiosa. Revista de Ciencias Sociales (CI), (16), 38-54. Recuperado de: https://www.redalyc.org/articulo.oa?id=70801603

Berchín, A. (1918). Convención de escuela sabática y V. M. Jóvenes en Valparaíso. $L a$ Revista Adventista, 18(2), 9-10.

Bianchi, S. (2004). Historia de las religiones en Argentina. Las minorías religiosas. Buenos Aires: Sudamericana.

Brauer, J. (2003). World Population and Membership-History and Projections. Aventistarchives.org [En línea] [Consultado el 16 de septiembre de 2019]. Recuperado de: http://documents.adventistarchives.org/Statistics/Other/MembershipAndPopulation Estimates2002.pdf

Brouchy, P. M. (1916). Corrientes. La Revista Adventista, 16(8), 14-15.

Brouchy, P. M. y Brouchy, A. de. (1915). Corrientes, Rep. Argentina. La Revista Adventista. 15(6), 10-11.

Brown, J. L. (1936). Take it, Lady! It'll interest you! South American Bulletin, 12(2), 3.

Brown, W. J. (1953). A Historical Study of the Seventh-day Adventist Church in Austral South America, 4 vols. (Tesis para optar al título de doctor en Filosofía). University of Southern California, California.

Bull, M. y Lockhart, K. (2007). Seeking a Sanctuary: Seventh-day Adventism and the American Dream (2 ed.). Bloomington, Indiana: Indiana University Press.

Carballo, F. H. (2017). La meretriz inmaculada: discurso antiprotestante y discurso anticatólico en la Colombia decimonónica. Bogotá: Editorial Universidad del Rosario.

Casebeer, J. G. (1916). Nueva escuela para niños. La Revista Adventista, 16(6), 8.

Ceriani Cernadas, C. y Lavazza, V. H. (2017). "Por la salvación de los indios": una travesía visual por la misión evangélica de Embarcación, Salta (1925-1975). Corpus, 7(2), 133. Recuperado de: http://journals.openedition.org/corpusarchivos/1964

Consejo Nacional de Educación (Argentina) (1946). El analfabetismo en la Argentina: Estudio comparativo desde 1869 a 1943. Ministerio de Educacion y Deportes, Presidencia de la Nación: Repositorio Institucional. [Consultado el 17 de enero de 2020]. 
https://books.google.com.ar/books/about/El_analfabetismo_en_la_Argentina.html?i d=-XzfAAAAMAAJ\&redir_esc $=\mathrm{y}$

De la Fuente Stranger, P. (2014). Misioneras y yaganas: colonialidad de género en el Beagle y canales australes (1867-1916). (Tesis para optar al grado de magíster en Estudios de Género y Cultura, mención Ciencias Sociales). Universidad de Chile, Santiago, Chile.

Escobar, M. (2017). Protestantes: la historia de la Reforma en quinientos años. Madrid: Mario Escobar Golderos.

Fernández, A. (2017). La ley argentina de inmigración de 1876 y su contexto histórico. Almanack, (17), 51-85. [Consultado el 6 de enero de 2020]. Recuperado de: https://www.scielo.br/scielo.php?script=sci_arttext\&pid=S2236$46332017000300051 \&$ thng=es

Flores, F. C. (2018). La colina de la esperanza: espacialidad y religiosidad en los orígenes de la aldea adventista de Puiggari. Diversa-Red de Estudios de la Diversidad Religiosa en Argentina. [Consultado el 6 de enero de 2020]. Recuperado de: http://www.diversidadreligiosa.com.ar/blog/la-colina-de-la-esperanza-espacialidady-religiosidad-en-los-origenes-de-la-aldea-adventista-de-puiggari/

Fortin, D. (2013). Ellen White, Women in Ministry and the Ordination of Women. Theology of Ordination Study Committee, 10 de noviembre. [Consultado el 27 de enero de 2020]. Recuperado de: https://www.adventistarchives.org/ellen-white,-women-inministry-and-the-ordination-of-women.pdf

La Voz del Colegio (1926). Frutos del Colegio. La Voz del Colegio, Núm. especial, 33-36. [Consultado el 5 de febrero de 2020]. Recuperado de: http://lavoz.uap.edu.ar/1926/mobile/index.html\#p=36

Fulton, A. (1907). Conferencia Argentina. La Revista Adventista, 7(12), 5.

Fulton, A. (1908, marzo). Entre los colportores. La Revista Adventista, 8(3), 23.

Gencer, A. (2010). Temperance still central to church's health message. Adventist News Network, 27 de enero. [Consultado el 27 de enero de 2020]. Recuperado de: https://news.adventist.org/en/all-news/news/go/2010-06-27/temperance-still-centralto-churchs-health-message/

Gobierno de la Ciudad Autónoma de Buenos Aires. (2010). Británica. Biblioteca Virtual Universal. [Consultado el 20 de enero de 2020]. Recuperado de: https://www.culturaargentina.org.ar/archivos/COLECTIVIDADES/Britanica.pdf

González-Bernaldo, P. e Hilaire-Pérez, L. (2015). Les savoirs-mondes. Rennes, Francia: Pressees universitaires de Rennes.

Greene de Oppegard, L. (1916). Sexta reunión bienal de la Conferencia Unión Sudamericana. La Revista Adventista, 16(3-4), 8.

Greenleaf, F. (2011). A Land of Hope: The growth of the Seventh-day Adventist Church in South America. Tatuí, San Pablo: Casa Publicadora Brasileira. [Consultado el 17 de enero de 2020]. Recuperado de: http://documents.adventistarchives.org/Books/ALOH2011.pdf

Griffin, K. (2014). Luz en Sudamérica. Los primersos pentecostales en Gualeguaychú, Entre Ríos, 1910-1917. (Tesis para optar al título de Doctora en Teología). Instituto Universitario ISEDET, Buenos Aires, Argentina.

Historical Sketches of the Foreing Missions of the Seventh-day Adventists (1886). Basilea, Suiza: Imprimerie Polyglotte. [Consultado el 17 de enero de 2020]. Recuperado de: http://documents.adventistarchives.org/Books/HSFM1886.pdf 
Iglesia Adventista del Séptimo Día (2017). Adventistas en el mundo. Adventistas.org. [En línea] [Consultado el 24 de enero de 2020]. Recuperado de: https://www.adventistas.org/es/institucional/los-adventistas/adventistas-en-elmundo/

James, K. R. y Hamilton, G. W. (2011). Ellen G. White \& National Moral Reform. Northwest Religious Liberty Association, 30 de julio. [Consultado el 27 de enero de 2011]. Recuperado de: https://nrla.com/ellen-g-white-national-moral-reform/

John, W.C. (1911). El Colegio Adventista del Plata. La Revista Adventista, 11(1), 14-15.

La Revista Adventista (1906a). A los colportores. La Revista Adventista, 6(1), p. 7.

La Revista Adventista (1906b). Colportoras. La Revista Adventista, 6(1), p. 8.

La Revista Adventista (1909). Notas editoriales. La Revista Adventista, 9(2), 16.

La Revista Adventista (1910). Extractos de los acuerdos del comité de la Conferencia Unión, tomados en el Colegio Adventista del Plata, Diamante, Entre Ríos, Argentina; octubre 21 a noviembre 14 de 1909. La Revista Adventista, 10(2), 13.

La Revista Adventista (1915). Noticias de la obra: Argentina-Prov. De B. Aires. La Revista Adventista, 15(4), 15.

La Revista Adventista (1916). Notas. La Revista Adventista, 16(1), 16.

La Revista Adventista (1918). Notas editoriales. La Revista Adventista, 18(19), 16.

Mangold, C. de (1907). Una experiencia en el colportaje. La Revista Adventista, 7(11), 7.

Maxwell, E. L. (1915). Ecos del campo. La Revista Adventista, 15(6), 8-9.

Mazariegos Herrera, H. M. C. (2018). La gestión de las emociones como un mecanismo de agencia de las mujeres metodistas de León. El Protestantismo: Perspectivas antropológicas, 5(7), 70-101.

Minniti Morgan, E. R. (2013). Colonia California y Galencia en el Pájaro Blanco. Serie Cuadernos Regionales. Córdoba: Eta Carinae. [Consultado el 30 de noviembre de 2017]. Recuperado de: https://historiadelaastronomia.files.wordpress.com/2013/03/colonia-california-ygalencia.pdf

Norheim, H. (2009). Mujeres al servicio de Cristo. Diálogo, 21(2-3), 17.

Office of Archives, Statistics and Research. (2016). Fundamentals beliefs of Seventh-day Adventists. Adventistarchives.org. [En línea] [Consultado el 10 de enero de 2020]. Recuperado de: https://www.adventistarchives.org/sdafundamentalbeliefs

Oppegard, O. y Oppegard, L. G. de. (1908). Conferencia Argentina: la obra en Buenos Aires. La Revista Adventista, 8(4), 47.

Peverini de Ampuero, O. (s.f.). Delantales blancos. S.d: Autor.

Peverini, H. (1988). En las huellas de la Providencia. Florida, Buenos Aires: ACES.

Pirota, J., Marconi, E., Giusti, A., Dinardi, G., Gómez, A. y Massa, C. (1991). Argentina. Los sistemas de Registro Civil y estadísticas vitales. Buenos Aires: Registro Civil y Capacidad de las Personas. [Consultado el 4 de julio de 2019]. Recuperado de: https://unstats.un.org/unsd/demographic/meetings/wshops/1991_Argentina_CRVS/ Docs/Argentina.pdf

Plenc, D., Scholtus, S.C., Di Dionisio, E. y Becerra, S. (2012). Misioneros fundacionales del Adventismo Sudamericano. Libertador San Martín, Entre Ríos: Editorial Universidad Adventista del Plata.

Post de Everist, L. (1910, mayo). La Escuela Sabática: El objeto e importancia de la escuela sabática. La Revista Adventista, 10(5), 8.

Post de Everist, L. (1910, junio). Las necesidades de nuestras escuelas sabáticas. La Revista 
Adventista, 10(6), 8.

Prensa UAP. (2014). La Lic. S[c]holtus es la primera mujer en defender una tesis doctoral en Teología en la UAP. Noticias, julio de 2014. [Consultado el 27 de enero de 2020]. Recuperado de: https://biblioteca.uap.edu.ar/2014/08/la-lic-sholtus-es-la-primeramujer-en-defender-una-tesis-doctoral-en-teologia-en-la-uap/

Prensa UAP. (2017). I Encuentro de Teólogas de la Unión Argentina. Noticias, 25 de agosto. [Consultado el 27 de enero de 2020]. Recuperado de: https://biblioteca.uap.edu.ar/2017/08/iencuentrodeteologas-ua/

Rodríguez, A. M. (2010). Tithing in the Writings of Ellen G. White. Silver Spring, Maryland: Stewardship Ministries Department of the General Conference of Seventh-day Adventists. [Consultado el 27 de enero de 2020]. Recuperado de: https://stewardship.adventist.org/stw-1060-\$2.50-tithing-in-the-writings-of-ellen-g.white.pdf

Roldán, A. F. (2007). Historia y posicionamientos sociopolíticos de los Hermanos Libres en la Argentina (1910-1937 y 1945-1955. Teología y Cultura. [Consultado el 6 de enero de 2020]. Recuperado de: http://www.teologos.com.ar/historia.htm

Scholtus, S. C. (2013). Liderazgo femenino. En los inicios de la Iglesia Adventista del Séptimo Día en la División Sudamericana. Florida, Buenos Aires: ACES.

Scholtus, S. C. (2018). Adventism in Argentina. En H. Gooren (ed.), Religions of the World. Encyclopedia of Latin American Religions (pp. 1-6). Springer, Cham, Suiza: Springer International Publishing AG.

Seiguer, P. (2007). 'Jamás he estado en casa'. Religión y nacionalidad entre los anglicanos en Argentina (1910-1930). Ponencia presentada en las XI Jornadas Interescuelas/Departamentos de Historia, 19 al 22 de septiembre, Tucumán, Argentina.

Seiguer, P. (2009). La Iglesia Anglicana en la Argentina y la colectividad inglesa. Identidad $y$ estrategias misionales, 1869-1930. (Tesis para optar al grado de doctor en Filosofía). Facultad de Filosofía y Letras de la Universidad de Buenos Aires, Buenos Aires, Argentina.

Seiguer, P. (2010a). El protestantismo histórico en la Argentina, 1870-1930: perspectivas historiográficas. Diversidad, 1(1), 100-112.

Seiguer, P. (2010b). Considerando la relación entre religión y nacionalidad: la Iglesia Anglicana en la Argentina como refugio de etnicidad. Ponencia presentada en el Seminario Interno de Humanidades de la Universidad de San Andrés. 19 de abril de 2010, Victoria, Entre Ríos, Argentina.

Seiguer, P. (2018). Las dificultades de la reducción a la unidad: la construcción del poder episcopal en la Iglesia Anglicana en la Argentina (1869-1920). Boletín del Instituto de Historia Argentina y Americana "Dr. Emilio Revignani”, № 48, 48-83.

Smith, U. (1881). General Conference. Adventist Review and Sabbath Herald, 58(25), 392393. [Consultado el 10 de enero de 2020]. Recuperado de: http://documents.adventistarchives.org/Periodicals/RH/RH18811220-V58-25.pdf

Spalding, A. W. (1947). Footprints of the Pioneers. Washington D. C.: Review and Herald. [Consultado el 17 de enero de 2020]. Recuperado de: http://documents.adventistarchives.org/Books/FOTP1947.pdf

Spalding, A. W. (1961). Origin and History of Seventh-day Adventist. 4 vols. Washington D. C.: Review and Herald. [Consultado el 17 de enero de 2020]. Recuperado de: http://documents.adventistarchives.org/Books/OH1961-01.pdf 
Spies, F. W. (1908). Conf. S. Catarina-Paraná. La Revista Adventista, 8(7), 63.

Stacey, B. (2004). Temperance Role of Adventists to Continue. Adventist New Network, 8 de agosto. [Consultado el 27 de enero de 2020]. Recuperado de: https://news.adventist.org/en/all-news/news/go/2004-08-08/temperance-role-ofadventists-to-continue/

Steele, G. (1906). La obra de nuestros colportores durante el primer trimestre de 1906. La Revista Adventista, 6(5-6), 6.

Strayer, B. E. (2002). Called to Witness. Adventist Review, 24 de enero. [Edición en línea] [Consultado el 24 de enero de 2020]. Recuperado de: https://www.adventistreview.org/archives/2002-1504/story1.html

The General Conference Bulletin (1895, March 3). 1(18), 446.

The General Conference Bulletin (1895, March 5), 1(20), 486.

Thomann, E. W. (1907, noviembre). Prov. de Tarapacá, Chile. La Revista Adventista, 7(11), 8.

Thomann, V. (1915, junio). La novena reunión general de la Conferencia Chilena. La Revista Adventista, 15(6), 11-12.

Thomann, V. (1916, mayo). Décima reunión anual de la Asociación Chilena. La Revista Adventista, 16(5), 6.

Timm, A. (2012). Seventh-day Adventists on women's ordination. A brief historical overview. Adventistarchives.org. [En línea] [Consultado el 10 de enero de 2020], Recuperado de: https://www.adventistarchives.org/seventh-day-adventists-onwomens-ordination.pdf

Timm, A. (2014). Seventh-day Adventists on women's ordination. A brief historical overview. Adventistarchives.org. [En línea] [Consultado el 10 de enero de 2020], Recuperado de: https://www.adventistarchives.org/seventh-day-adventists-onwomens-ordination-a-brief-historical-overview.pdf

Town, N. Z. (1908a). Conferencia Unión Sud Americana. La Revista Adventista, 8(4), 33.

Town, N. Z. (1908b). Conferencia Argentina: por Santa Fe y La Paz, Entre Ríos. La Revista Adventista, 8(7), 65.

Town, N. Z. (1910). La Conferencia Unión Sudamericana. La Revista Adventista, 10(4), 1213.

Vance, L. L. (1999). Seventh-day Adventism in Crisis: Gender and Sectarian Change in an Emerging Religion. Urbana and Chicago: University of Illinois Press.

Viano, H. L. (2011). La primera Iglesia Metodista en Lomas de Zamora. Una misión protestante en el Buenos Aires rural (1891-1910). Sitio web Teologos.com.ar [Consultado el 8 de enero de 2020]. Recuperado de: http://www.teologos.com.ar/historia.htm

Viera, J. C. (1993). Los Adventistas del Séptimo día en América Latina: sus comienzos, su crecimiento, sus desafíos. (Tesis para optar al grado de doctor en Ministerio). Fuller Theological Seminary, Pasadena, California, Estados Unidos.

Villalpando, W. L. (ed.). (1970). Las iglesias del trasplante. Protestantismo de inmigración en la Argentina. Buenos Aires: Centro de Estudios Cristianos.

Westphal, F. H. (1906). Donaciones para la imprenta. La Revista Adventista, 6(4), 2.

Westphal, F. H. (1908). Conferencia Chilena, notas del campo. La Revista Adventista, 8(1), 3.

Westphal, F. H. (1927). Pioneering in the Neglected Continent. Nashville, Tenn.: Southern Publishing Association. 
Westphal, F. H. (1997). Pionero en Sudamérica. (Trad. Silvia Scholtus de Roscher). Libertador San Martín, Entre Ríos: Centro de Investigación White.

Westphal, J. W. (1915). La reunión anual chilena. La Revista Adventista, 15(5), 9.

Westphal, J. W. (1916). La obra en Montevideo. La Revista Adventista, 16(8), 13-14.

Westphal, M. T. de (1917, octubre). Escuela de iglesia de Pitrufquén, Chile. La Revista Adventista, 17(10), 9-10.

White, E. H. (1878). Address and Appeal, Setting For the the Importance of Missionary Work. The Review and Herald, 52(25), 1-2. [Consultado el 10 de enero de 2017]. Recuperado de: http://documents.adventistarchives.org/Periodicals/RH/RH18781219-V52-25.pdf

White, E. H. (1885). To our missionary workers. Review and Herald, 62(48), 753-754. [Consultado el 5 de febrero de 2020]. Recuperado de: http://documents.adventistarchives.org/Periodicals/RH/RH18851208-V62-48.pdf

White, E. H. (1898). The Laborer is Worthy of His Hire. Manuscript 43a, 22 de marzo de 1898. [Consultado el 5 de febrero de 2020]. Recuperado de: https://egwwritings.org/?ref=en_Ms43a-1898.4\&para=6076.9

White, E. H. (1899). Paying Women Workers. Manuscript 149, 24 de octubre, 1899.

White, E. H. (24 de julio de 1910). [Carta para A. G. Daniells]. Letter 84, 1910. Escritos Beta [En línea] [Consultado el 10 de enero de 2017]. Recuperado de: https://egwwritings.org/?ref=en_Lt84-1910\&para=10910.2

White, E. H. (1978). El evangelismo. Florida, Buenos Aires: ACES. 